\title{
Near-equiatomic high-entropy decagonal quasicrystal in $\mathrm{Al}_{20} \mathrm{Si}_{20} \mathrm{Mn}_{20} \mathrm{Fe}_{20} \mathrm{Ga}_{20}$
}

\author{
Haikun $\mathrm{Ma}^{1 \dagger}$, Liangqun Zhao ${ }^{1 \dagger}$, Zhi-Yi Hu${ }^{2}$, Dinghao Miao ${ }^{1}$, Ruixuan $\mathrm{Li}^{1}$, Tulai Sun ${ }^{3}, \mathrm{He} \mathrm{Tian}^{3}$, \\ Tiantian Zhang ${ }^{1}$, Hua $\mathrm{Li}^{1}$, Yong Zhang ${ }^{1}$ and Zhanbing $\mathrm{He}^{1^{*}}$
}

\begin{abstract}
High-entropy alloys (HEAs) contain multiple principal alloying elements, but usually with simple crystal structures. Quasicrystals are structurally complex phases, but are generally dominated by only one element. However, nearequiatomic high-entropy quasicrystals have rarely been reported because they are difficult to prepare experimentally and predict theoretically. Therefore, the preparation and crystal structures of near-equiatomic high-entropy quasicrystals have drawn much interest. We report a quinary decagonal quasicrystal (DQC) with near-equiatomic alloying elements in $\mathrm{Al}_{20} \mathrm{Si}_{20} \mathrm{Mn}_{20} \mathrm{Fe}_{20} \mathrm{Ga}_{20}$ melt-spun ribbons, which is the first to our knowledge. Meanwhile, the structural features of the DQC are characterized in detail. The configurational entropy of both the alloy and DQC satisfies the entropy-based criterion for HEAs, suggesting a high-entropy DQC. Our findings provide a new strategy to develop high-entropy quasicrystals.
\end{abstract}

Keywords: high-entropy alloys, decagonal quasicrystal, highentropy quasicrystals, melt-spun ribbons, high-angle annular dark-field scanning transmission electron microscopy

\section{INTRODUCTION}

The first icosahedral quasicrystal was discovered by Shechtman in quenched Al-Mn alloys in 1984 [1], and hundreds of quasicrystals have since been reported [2]. Quasicrystals were mainly discovered in binary and ternary Al-based alloys [2-7], usually with an Al content of 60 at $\%$ to 85 at $\%$ (at\%, atomic percent) [8]. In addition, quasicrystals were found in other systems such as $\mathrm{Mg}$ based and Ga-based alloys [9-12]. Most quasicrystals are dominated by only one element; quasicrystals with multiple principal alloying elements have rarely been dis- covered.

High-entropy alloys (HEAs) were first independently reported in 2004 by Yeh et al. [13] and Cantor et al. [14]. Different from the traditional alloys, HEAs are not based on one or two major elements, but are composed of multiple principal alloying elements. They usually contain at least five principal elements in equal or near-equal atomic percentages [15]. The definition of HEAs has been extended from equiatomic alloys to alloys with sufficiently high configurational entropy $\left(\Delta S_{\text {conf }}\right)$ to overcome the effect of enthalpy [16]. Alloys with a $\Delta S_{\text {conf }}$ greater than $1.5 R\left(R=8.31 \mathrm{~J} \mathrm{~K}^{-1} \mathrm{~mol}^{-1}\right.$, the gas constant $)$ are usually defined as HEAs $[17,18]$, and non-equiatomic HEAs have also been developed [16].

The phase structures of reported HEAs contain solid solutions, intermetallics, and amorphous phases $[19,20]$. Among them, the face-centred cubic (FCC) [14,21-25] and body-centred cubic (BCC) [26-29] solid-solution HEAs are by far the most extensively investigated. Furthermore, hexagonal close-packed (HCP) structures [30$35]$, ordered intermetallic phases [16,36], complicated compounds [37], and metallic glasses [38] have also been observed in HEAs.

High-entropy quasicrystals are highly desired because they combine structural and compositional complexity. Although Takeuchi et al. [39] found an icosahedral quasicrystal in the heat-treated melt-spun amorphous alloys of $\mathrm{Ti}_{33.33} \mathrm{Zr}_{33.33} \mathrm{Hf}_{13.33} \mathrm{Ni}_{20}$ and $\mathrm{Zr}_{30} \mathrm{Hf}_{30} \mathrm{Ni}_{15} \mathrm{Cu}_{10} \mathrm{Ti}_{15}$, the $\Delta S_{\text {conf }}$ of these alloys are $1.42 R$ and $1.37 R$, respectively. These are somewhat lower than $1.5 R$, the criterion for HEA definition according to Yeh et al. $[17,18]$; thus, these alloys can be classified as medium-entropy alloys (MEAs)

\footnotetext{
${ }^{1}$ State Key Laboratory for Advanced Metals and Materials, University of Science and Technology Beijing, Beijing 100083, China

${ }^{2}$ Nanostructure Research Centre (NRC); State Key Laboratory of Advanced Technology for Materials Synthesis and Processing, Wuhan University of Technology, Wuhan 430070, China

${ }^{3}$ School of Materials Science and Engineering, Zhejiang University, Hangzhou 310027, China

${ }^{\dagger}$ These authors contributed equally to this paper.

* Corresponding author (email: hezhanbing@ustb.edu.cn)
} 
[15] instead of HEAs. Takeuchi et al. [39] considered $\mathrm{Pd}_{20} \mathrm{Pt}_{20} \mathrm{Ni}_{20} \mathrm{U}_{20} \mathrm{Si}_{20}$ as a candidate for a high-entropy quasicrystal. However, uranium is a radioactive element, which is hard to handle in a conventional experimental environment. They also mentioned that it is difficult to explore high-entropy quasicrystals from Al-based quasicrystal alloys because there are no elements that can effectively replace $\mathrm{Al}$ in the periodic table [39]. Therefore, preparing high-entropy quasicrystals is still a great challenge.

We report a high-entropy decagonal quasicrystal (DQC) in $\mathrm{Al}_{20} \mathrm{Si}_{20} \mathrm{Mn}_{20} \mathrm{Fe}_{20} \mathrm{Ga}_{20}$ melt-spun ribbons, which is the first to our knowledge. Alloys for searching highentropy DQCs are designed by referring to similar structural blocks of DQCs, the difference in atomic radius $(\delta)$ and the enthalpy of mixing $\left(\Delta H_{\text {mix }}\right)$. In general, the formation of a single-phase solid solution corresponds to the region of $-15 \mathrm{~kJ} \mathrm{~mol}^{-1}<\Delta H_{\text {mix }}<5 \mathrm{~kJ} \mathrm{moL}^{-1}$ and $0<\delta$ $<6.6$ [16]. A further increase in $\delta$ and decrease in the negative $\Delta H_{\text {mix }}$ value result in the appearance of different phases such as intermetallic and bulk metallic glasses (BMGs) $[16,40]$. We found a similarity between Ga-Mn [41] and Al-Cr-Fe-Si [42] DQCs by comparing the 2-nm decagons of DQCs in different alloys. In addition, $\delta=$ $7.67 \%(>\quad 6.6 \%)$ and $\Delta H_{\text {mix }}=-25.6 \mathrm{~kJ} \mathrm{~mol}^{-1}$ $\left(<-15 \mathrm{~kJ} \mathrm{~mol}^{-1}\right)$ in $\mathrm{Al}_{20} \mathrm{Si}_{20} \mathrm{Mn}_{20} \mathrm{Fe}_{20} \mathrm{Ga}_{20}$, suggesting it is easier to form intermetallic compounds than solid solutions [16]. This is consistent with the features of intermetallic compounds of quasicrystals. Therefore, we selected the quinary $\mathrm{Al}-\mathrm{Si}-\mathrm{Mn}-\mathrm{Fe}-\mathrm{Ga}$ system for study and found a near-equiatomic high-entropy DQC with a periodicity of $1.23 \mathrm{~nm}$ in the $\mathrm{Al}_{20} \mathrm{Si}_{20} \mathrm{Mn}_{20} \mathrm{Fe}_{20} \mathrm{Ga}_{20}$ meltspun ribbons. The structural characteristics of the highentropy DQC were investigated in detail using high-angle annular dark field scanning transmission electron microscopy (HAADF-STEM) images at an atomic resolution.

\section{EXPERIMENTAL SECTION}

\section{Materials}

Al (99.99 wt\%), Si (99.3 wt\%), Mn (99.9 wt\%), Fe (99.9 wt\%) and $\mathrm{Ga}(99.9 \mathrm{wt} \%)$ metals were obtained from Beijing Cuibolin Nonferrous Metal Technology Development Center Co., Ltd. Copper grid was purchased from Beijing Zhongxingbairui Technology Co., Ltd.

\section{Preparation of quasicrystals}

An Al-Si-Mn-Fe-Ga alloy ingot of around $1 \mathrm{~kg}$ with a nominal composition of $\mathrm{Al}_{20} \mathrm{Si}_{20} \mathrm{Mn}_{20} \mathrm{Fe}_{20} \mathrm{Ga}_{20}$ was ob- tained by first melting high-purity elements in an induction furnace under an argon atmosphere, and then pouring the molten alloy into a graphite crucible in the furnace to form an ingot. Several small sample pieces from the cast ingot of the alloy were subjected to the single-wheel melt-spun treatment under a copper wheel speed of $25 \mathrm{~m} \mathrm{~s}^{-1}$, and then the melt-spun ribbons were obtained.

\section{Characterizations}

The specimens for TEM observation were prepared via three methods: powders spread onto a 3-mm-diameter copper grid covered with a holey carbon film, ion milling, and a focused ion beam (FIB). The secondary electron images were obtained with a ZEISS GeminiSEM 300 scanning electron microscope (SEM). The selected-area electron diffraction (SAED) patterns and energy dispersive X-ray spectroscopy (EDS) measurements were performed with an FEI Tecnai F30 transmission electron microscope. Meanwhile, the atomic-resolution structural investigations were performed on a Thermo Fisher Titan Themis microscope fitted with aberration correctors for the imaging lens and the probe forming lens, Super-X EDX system, operated at $300 \mathrm{kV}$. The HAADF-STEM images were recorded with drift-corrected frame integration (DCFI), which minimizes drift and achieves a high signal-to-noise ratio via calculating and correcting the drift from cross correlation.

\section{RESULTS AND DISCUSSION}

First, we used both X-ray diffraction (XRD) and SAED patterns of powder samples to check the phases of the $\mathrm{Al}_{20} \mathrm{Si}_{20} \mathrm{Mn}_{20} \mathrm{Fe}_{20} \mathrm{Ga}_{20}$ melt-spun ribbons. Some XRD peaks of the ribbons in Fig. $1 \mathrm{~h}$ are quite similar to those of the DQCs of Al-Ni-Co [43], Al-Ni-Fe [43], and Al-Co$\mathrm{Cu}$ [44], implying the possible existence of DQCs (also see the comparison of XRD in Fig. S1). This was further verified directly by the SAED patterns. The free side is Side A in Fig. 1a, and the side of the ribbon close to the copper roller is Side B. The grain sizes on Side B are evidently different from those on Side A because the cooling rate of Side A is lower than that of Side B. To determine whether the DQC is on Side A or B, we prepared TEM samples from both sides using an FIB instrument. We found that the DQC exists on both sides of the melt-spun ribbon. Fig. 1b, c show the bright-field TEM images of DQC particles from Side B viewed along the tenfold and twofold zone axes of the DQC, respectively. The DQC grains are on the nanoscale without an evident polygonal outline. Fig. $1 \mathrm{~d}-\mathrm{f}$ show the typical 

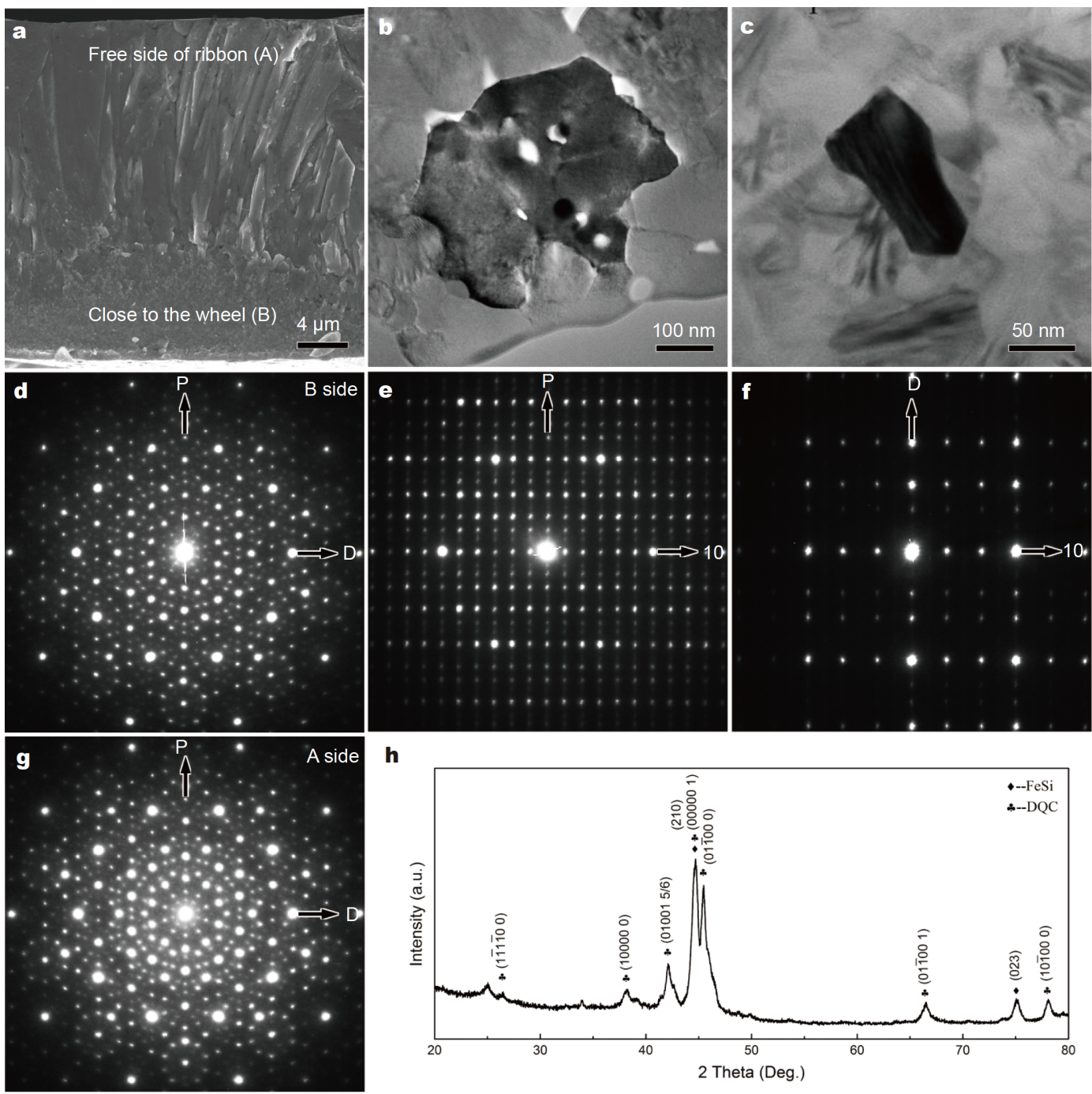

h

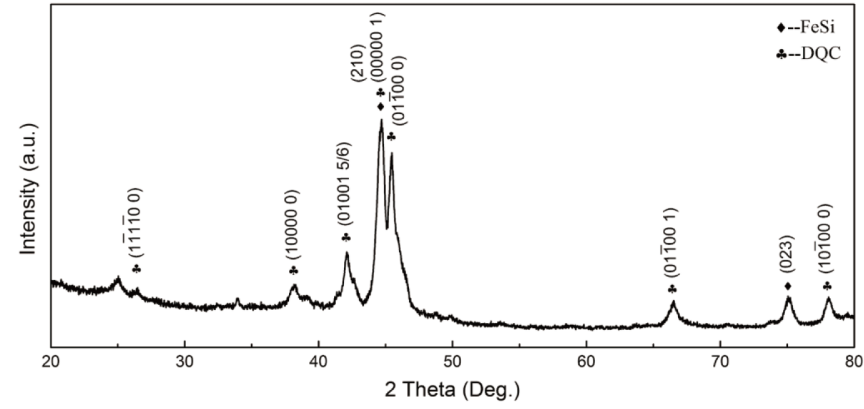

Figure 1 Crystalline grains and DQC SAED patterns of the $\mathrm{Al}_{20} \mathrm{Si}_{20} \mathrm{Mn}_{20} \mathrm{Fe}_{20} \mathrm{Ga}_{20}$ melt-spun ribbon. (a) Cross-sectional SEM image of melt-spun ribbon. (b, c) TEM images of quasicrystal grains. (d) SAED pattern along the tenfold zone axis from Side B. (e) SAED pattern of one twofold zone axis. (f) SAED pattern of another twofold zone axis at $18^{\circ}$ from the SAED in (e). (g) SAED pattern along the tenfold zone axis of DQC in free side of the ribbon (Side A). (h) XRD patterns obtained from the $\mathrm{Al}_{20} \mathrm{Si}_{20} \mathrm{Mn}_{20} \mathrm{Fe}_{20} \mathrm{Ga}_{20}$ melt-spun ribbons.

SAED patterns of the DQC along the tenfold and two twofold zone axes from Side B. The diffraction spots in Fig. 1d show evident tenfold symmetry, implying it is a DQC [45]. Two representative twofold zone axes of the DQC in Fig. 1e, f are normal to the one in Fig. 1d, and each one contains periodic rows of diffraction spots (along the horizontal direction), corresponding to a periodicity of $1.23 \mathrm{~nm}$ in real space. Fig. $1 \mathrm{~g}$ shows the typical SAED pattern along the tenfold zone axis of one DQC grain on the free side of the ribbon (Side A), where there is no obvious difference between Side A and Side B. The average DQC composition is determined to be
$\mathrm{Al}_{20.5} \mathrm{Si}_{19.0} \mathrm{Mn}_{20.9} \mathrm{Fe}_{26.3} \mathrm{Ga}_{13.3}$, implying it is a multipleprincipal-element DQC, different from any previously reported single-principal-element DQC [46]. The values of $\Delta S_{\text {conf }}$ for the $\mathrm{Al}_{20} \mathrm{Si}_{20} \mathrm{Mn}_{20} \mathrm{Fe}_{20} \mathrm{Ga}_{20}$ alloy and the DQC phase are calculated to be $1.61 R$ and $1.59 R$, respectively. These are both greater than $1.5 R$, thus satisfying the entropy-based definition of HEAs [16], which verifies that they are HEA and high-entropy phase, respectively. Note that the $\mathrm{Al}_{20} \mathrm{Si}_{20}-\mathrm{Mn}_{20} \mathrm{Fe}_{20} \mathrm{Ga}_{20}$ is a multiphase HEA, where crystal phases such as $(1 / 0,2 / 1)$-type approximant of DQC [47], FeSi/MnSi-type (cubic, space group: $P 2_{1} 3$ (198), PDF Card: 38-1397/42-1487) crystal are also found 
in addition to the DQC. We do not present these crystals here because they are not the focus of this article.

To reveal the structural features of the high-entropy DQC, we obtained an atomic resolution HAADF-STEM image along the tenfold zone axis, as shown in Fig. 2. The structural blocks are depicted with sky-blue polygons by linking the centres of the smallest decagons with a diameter of $\sim 0.47 \mathrm{~nm}$. The most basic structural tiles with an edge length of $0.62 \mathrm{~nm}$ are squashed hexagon $(\mathrm{H})$, star (S), boat (B), bowtie (BT), and decagon (D), as indicated at the bottom of Fig. 2a. We note that all of these basic structural blocks except D can further form several $\mathrm{S}$ tiles, shield-like tiles (SLTs) [48], concave decagons (CDs), and regular decagons, as seen clearly by filling different colours into the different types of tiles in Fig. 2b. Most of the structural blocks in Fig. $2 \mathrm{~b}$ are D tiles, along with several types (see in Fig. 3 below). The one containing three $\mathrm{H}$ tiles and one BT tile dominates (Fig. 2b), which is highlighted in light green. The $\mathrm{D}$ tiles can overlap with an area of one $\mathrm{H}$ tile or share one edge to generate a distance of 1.18 or $1.91 \mathrm{~nm}$ (nearly $\tau$ times the former, $\tau=1.618$ ) between their centres. Fig. $2 \mathrm{c}$ shows the projected structural models of the basic structural blocks of BT, H, B, and $S$ based on the atomic-scale HAADF-STEM image. The centres of the smallest $\mathrm{D}$ clusters are assigned to heavier elements such as $\mathrm{Ga}, \mathrm{Fe}$, and $\mathrm{Mn}$ because of the higher intensities in the HAADF-STEM image [49]. However, we cannot distinguish them owing to the difficulty in achieving atomic-resolution element mapping. Geometric configurations of different S, CD, and SLT
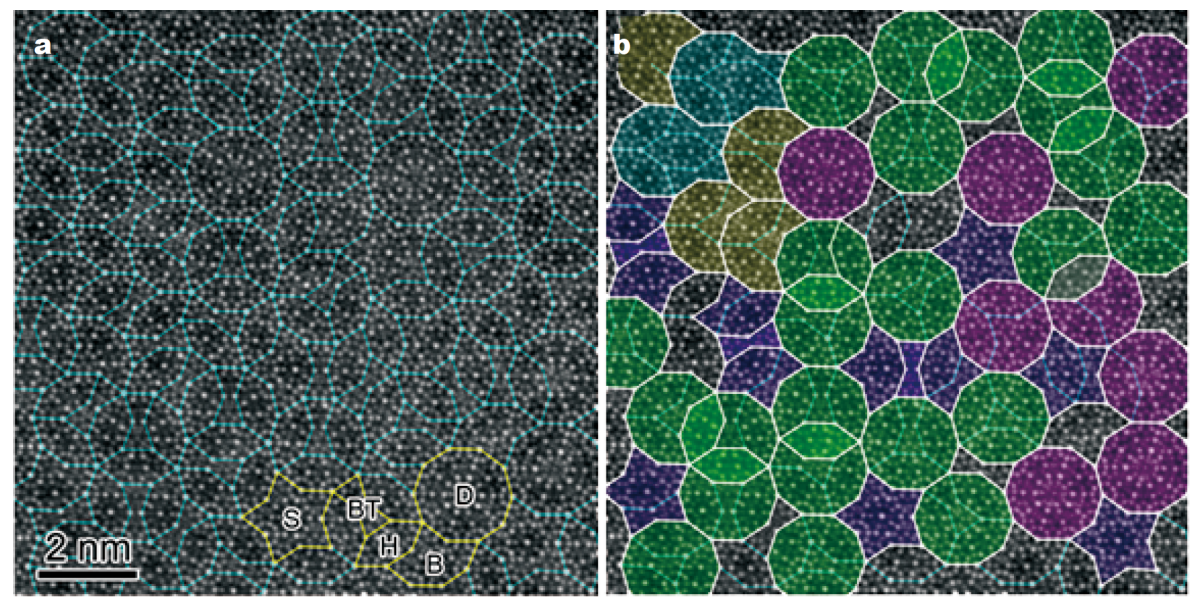

c

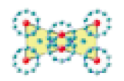

BT

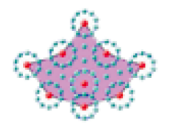

B

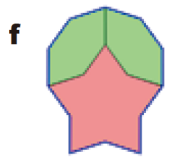

SLT-I

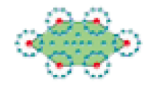

$\mathrm{H}$

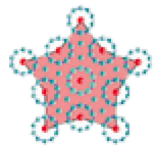

$\mathrm{S}$

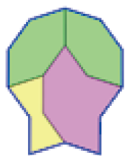

SLT-II

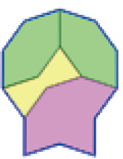

SLT-III d

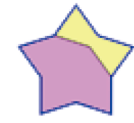

S-I

e

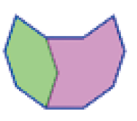

Concave D-I

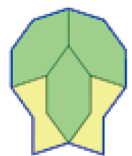

SLT-IV

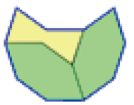

Concave D-II

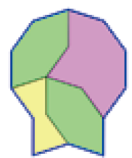

SLT-V

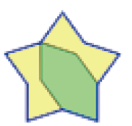

S-II

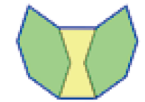

Concave D-III

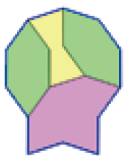

SLT-VI

- $\mathrm{Mn} / \mathrm{Fe} / \mathrm{Ga} \quad \cdot \mathrm{Al} / \mathrm{Si}$

Figure 2 HAADF-STEM image and structural blocks of Al-Si-Mn-Fe-Ga DQC. (a) HAADF-STEM image along the tenfold axis of Al-Si-Mn-Fe-Ga DQC. (b) Colour-tiled HAADF-STEM image along the tenfold axis of Al-Si-Mn-Fe-Ga DQC. (c) Four basic structural blocks: BT, B, H, S. (d) Two types of S tiles. (e) Three types of concave decagon tiles. (f) Six types of SLTs. 
kinds are schematically summarized in Fig. 2d-f. All types of each kind of tile have the same outline (highlighted in blue polygons). These tiles are composed of smaller tiles, therefore, owning the superiority over the smaller tiles in concision in describing the structural tiling [42].

The D clusters with a diameter of $\sim 2.0 \mathrm{~nm}$ were considered the most important tiles in Al-based DQCs $[7,42,46]$. Therefore, in Fig. 3 we summarize the $2.0-\mathrm{nm}$ D clusters in the $\mathrm{Al}_{20} \mathrm{Si}_{20} \mathrm{Mn}_{20} \mathrm{Fe}_{20} \mathrm{Ga}_{20}$ DQC and propose the corresponding structural models. The common feature of these $2.0-\mathrm{nm} \mathrm{D}$ clusters is that the $0.47-\mathrm{nm} \mathrm{D}$ clusters are located at the periphery of the $2.0-\mathrm{nm} \mathrm{D}$ clusters. The tenfold symmetry of the $2.0-\mathrm{nm}$ D cluster is broken gradually as the number of 0.47 -nm clusters in the inner area increases, as seen from the left to right $\mathrm{D}$ clusters in Fig. 3. These structural features are quite similar to those of the $\mathrm{Al}_{60} \mathrm{Cr}_{20} \mathrm{Fe}_{10} \mathrm{Si}_{10}$ DQC [42] and different from other types of DQCs such as those in Al-Co-Ni, Al-Pd-Mn, and Al-Co-Cu alloys [46].

Phase prediction has long been a hot topic of discussion. The atomic size, crystal structure, valence electron concentration, and electronegativity of binary alloys were considered to have a major effect on phase formation according to the Hume-Rothery criterion [50], which was later amended by Zhang et al. [16,51] to extend to multi- component alloys. The $\delta$ and $\Delta H_{\text {mix }}$ were initially used to predict phase formation in the multi-component alloys. Later, the effect of mixing entropy was also considered in phase formation, and then the supplementary criterion $\Omega=\frac{T_{\mathrm{m}}^{\text {mix }} \Delta S_{\text {mix }}}{\mid \Delta H_{\text {mix }}}$, where $\Delta S_{\text {mix }}$ is the entropy of mixing, was proposed on the basis of the Gibbs free energy formula [51]. The solid solution phase usually forms when $\delta$ is smaller than $6.6 \%, \Delta H_{\text {mix }}$ is between -15 and $5 \mathrm{~kJ} \mathrm{~mol}^{-1}$, and $\Omega$ is greater than 1.1 [51-53]. However, the intermetallic and amorphous phases usually form at a larger $\delta$ and lower values of $\Delta H_{\text {mix }}$ and $\Omega$ [51-53].

Therefore, we calculated the $\Delta H_{\text {mix }}, \delta, S_{\text {conf }} / R$, and $\Omega$ values of the $\mathrm{Al}_{20} \mathrm{Si}_{20} \mathrm{Mn}_{20} \mathrm{Fe}_{20} \mathrm{Ga}_{20}$ alloy and the DQC phase in this alloy, which are summarized in Table 1. After adding the points for $\mathrm{Al}_{20} \mathrm{Si}_{20} \mathrm{Mn}_{20} \mathrm{Fe}_{20} \mathrm{Ga}_{20}$ and the high-entropy DQC to the $\delta-\Delta H_{\text {mix }}$ plot summarized by Ye et al. [53] (Fig. 4a), we found that neither the alloy nor the DQC phase belong to any classified areas. Combined with the fact that $\mathrm{Al}_{20} \mathrm{Si}_{20} \mathrm{Mn}_{20} \mathrm{Fe}_{20} \mathrm{Ga}_{20}$ is a multiphase HEA, the multiphase area in the $\delta-\Delta H_{\text {mix }}$ diagram in [53] could be extended to include the current alloy, as seen in Fig. 4a. However, both the $\mathrm{Al}_{20} \mathrm{Si}_{20} \mathrm{Mn}_{20} \mathrm{Fe}_{20} \mathrm{Ga}_{20}$ alloy and the DQC phase therein are located in the amorphous area of the $\delta$ - $\Omega$ diagram by Yang et al. [51] (Fig. 4b). Considering the intermetallic feature of the DQC, we have
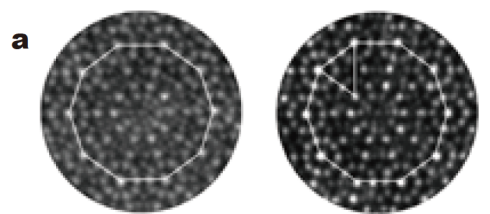

b
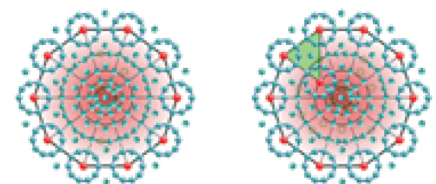

C

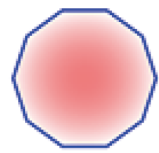

D-I

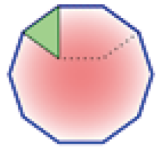

D-II
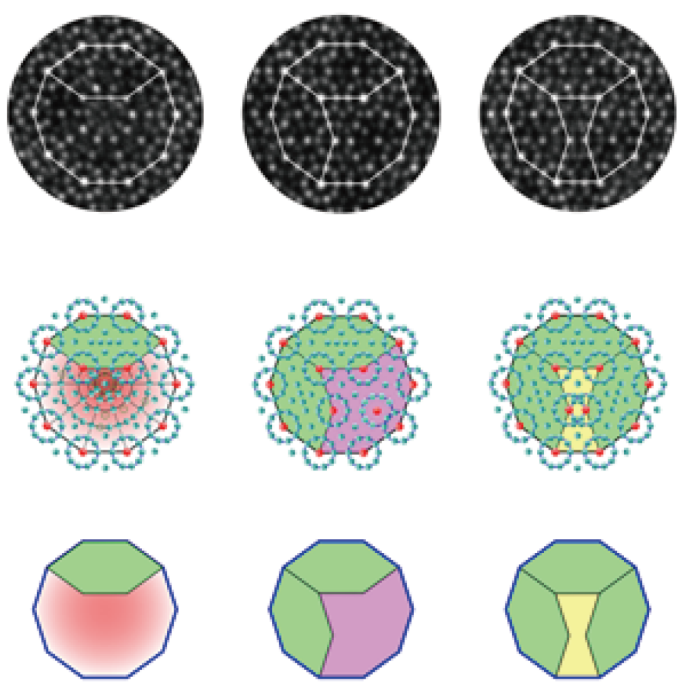

D-III
D-IV

$\mathrm{D}-\mathrm{V}$

$\cdot \mathrm{Mn} / \mathrm{Fe} / \mathrm{Ga} \quad \cdot \mathrm{Al} / \mathrm{Si}$

Figure $3 \mathrm{D}$ clusters with the tenfold symmetry broken gradually. (a) Five types of D clusters. (b) Corresponding D clusters with the atoms superimposed. (c) Structural schematics of five types of D clusters. The tenfold symmetry of D clusters is broken gradually as the number of 0.47 -nm D clusters increases inside (from left to right in the row of (a)). 

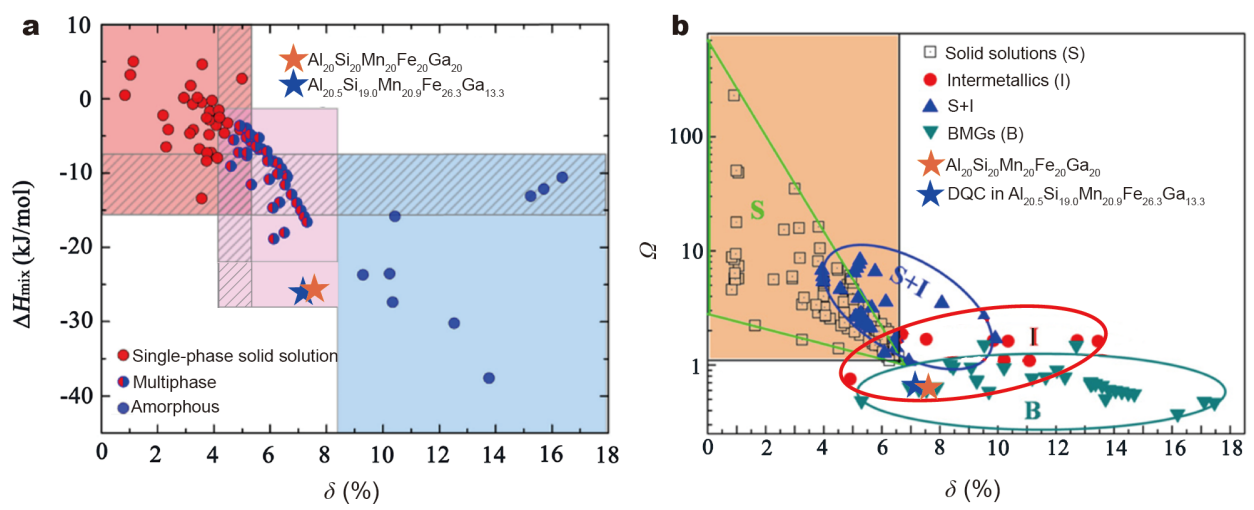

Figure 4 Positions of $\mathrm{Al}_{20} \mathrm{Si}_{20} \mathrm{Mn}_{20} \mathrm{Fe}_{20} \mathrm{Ga}_{20}$ and $\mathrm{Al}_{20.5} \mathrm{Si}_{19.0} \mathrm{Mn}_{20.9} \mathrm{Fe}_{26.3} \mathrm{Ga}_{13.3}$ in the $\delta$ - $\Delta H_{\text {mix }}$ (a) and $\delta$ - $\Omega$ (b) plots. We use stars to indicate the additional positions reported in this paper. (a) Adapted with the permission from Ref. [53], Copyright 2016, Elsevier; (b) adapted with the permission from Ref. [51], Copyright 2012, Elsevier.

Table 1 Calculated values of $\Delta H_{\text {mix }}\left(\mathrm{kJ} \mathrm{mol}^{-1}\right), \delta, S_{\text {conf }} / R$, and $\Omega$

\begin{tabular}{ccccc}
\hline & $\Delta H_{\text {mix }}\left(\mathrm{kJ} \mathrm{mol}{ }^{-1}\right)$ & $\delta(\%)$ & $S_{\text {conf }} / R$ & $\Omega$ \\
\hline $\mathrm{Al}_{20} \mathrm{Si}_{20} \mathrm{Mn}_{20} \mathrm{Fe}_{20} \mathrm{Ga}_{20}$ & -25.60 & 7.67 & 1.61 & 0.65 \\
DQC in $\mathrm{Al}_{20} \mathrm{Si}_{20} \mathrm{Mn}_{20} \mathrm{Fe}_{20} \mathrm{Ga}_{20}$ & -26.08 & 7.13 & 1.59 & 0.68 \\
\hline
\end{tabular}

extended the intermetallic area to include the DQC point in Fig. 4b. Therefore, the high-entropy quasicrystal alloy studied in this paper has expanded the area that is the criterion for HEA phases, and is complementary to the HEA-related $\delta$ - $\Delta H_{\text {mix }}$ and $\delta-\Omega$ diagrams.

\section{CONCLUSIONS}

A near-equiatomic multi-component high-entropy DQC of $\mathrm{Al}_{20.5} \mathrm{Si}_{19.0} \mathrm{Mn}_{20.9} \mathrm{Fe}_{26.3} \mathrm{Ga}_{13.3}$ was successfully synthesized in $\mathrm{Al}_{20} \mathrm{Si}_{20} \mathrm{Mn}_{20} \mathrm{Fe}_{20} \mathrm{Ga}_{20}$ melt-spun ribbons through a strategy using the structural similarity of different DQCs and the previously used factors of the $\delta$ and $\Delta H_{\text {mix }}$. We studied the structural features of the high-entropy DQC along the tenfold axis in detail through HAADF-STEM imaging at atomic resolution. The most basic structural tiles of the high-entropy DQC are polygons with an edge length of $0.62 \mathrm{~nm}$ such as squashed hexagon, star, boat, bowtie, and decagon. We proposed the corresponding projected structural models on the basis of the HAADFSTEM imaging. Among these models, the decagons with a diameter of $2.0 \mathrm{~nm}$ have five types with their tenfold symmetry broken gradually as the number of $0.47-\mathrm{nm} \mathrm{D}$ clusters inside increases, which is analogous to the Albased DQC in Al-Cr-Fe-Si alloys.

Received 21 April 2020; accepted 26 June 2020; published online 21 September 2020

1 Shechtman D, Blech I, Gratias D, et al. Metallic phase with long- range orientational order and no translational symmetry. Phys Rev Lett, 1984, 53: 1951-1953

2 Steurer W. Quasicrystals: What do we know? What do we want to know? What can we know? Acta Crystlogr A Found Adv, 2018, 74: $1-11$

3 Ma XL, Kuo KH. Decagonal quasicrystal and related crystalline phases in slowly solidified Al-Co alloys. Metall Trans A, 1992, 23: 1121-1128

4 Chattopadhyay K, Ranganathan S, Subbanna GN, et al. Electron microscopy of quasi-crystals in rapidly solidified Al-14\% $\mathrm{Mn}$ alloys. Scripta Metall, 1985, 19: 767-771

5 Dubost B, Lang JM, Tanaka M, et al. Large AlCuLi single quasicrystals with triacontahedral solidification morphology. Nature, 1986, 324: 48-50

6 Tsai AP, Inoue A, Masumoto T. A stable decagonal quasicrystal in the Al-Cu-Co system. Mater Trans, 1989, 30: 300-304

7 Dong C, Chen W, Wang Y, et al. Formation of quasicrystals and metallic glasses in relation to icosahedral clusters. J Non-Crystal Solids, 2007, 353: 3405-3411

8 Grushko B, Velikanova TY. Stable and metastable quasicrystals in Al-based alloy systems with transition metals. J Alloys Compd, 2004, 367: 58-63

9 Sato TJ, Abe E, Tsai AP. A novel decagonal quasicrystal in Zn-MgDy system. Jpn J Appl Phys, 1997, 36: L1038-L1039

10 Sato TJ, Abe E, Tsai AP. Composition and stability of decagonal quasicrystals in the Zn-Mg-rare-earth systems. Philos Mag Lett, 1998, 77: 213-219

11 Ryomaezawa YK, Kaneko H, Ishimasa T. Cu-based icosahedral quasicrystal formed in Cu-Ga-Mg-Sc alloys. Philos Mag Lett, 2002, 82: 483-493

$12 \mathrm{Ge}$ SP, Kuo KH. Icosahedral and stable decagonal quasicrystals in $\mathrm{Ga}_{46} \mathrm{Fe}_{23} \mathrm{Cu}_{23} \mathrm{Si}_{8}, \mathrm{Ga}_{50} \mathrm{Co}_{25} \mathrm{Cu}_{25}$ and $\mathrm{Ga}_{46} \mathrm{~V}_{23} \mathrm{Ni}_{23} \mathrm{Si}_{8}$. Philos Mag Lett, 1997, 75: 245-254

13 Yeh JW, Chen SK, Lin SJ, et al. Nanostructured high-entropy alloys 
with multiple principal elements: Novel alloy design concepts and outcomes. Adv Eng Mater, 2004, 6: 299-303

14 Cantor B, Chang ITH, Knight P, et al. Microstructural development in equiatomic multicomponent alloys. Mater Sci Eng-A, 2004, 375-377: 213-218

15 Yeh JW. Recent progress in high-entropy alloys. Ann Chim Sci Mat, 2006, 31: 633-648

16 Zhang Y, Zuo TT, Tang Z, et al. Microstructures and properties of high-entropy alloys. Prog Mater Sci, 2014, 61: 1-93

17 Yeh JW. Alloy design strategies and future trends in high-entropy alloys. JOM, 2013, 65: 1759-1771

18 Gao MC, Yeh JW, Liaw PK, et al. High-entropy Alloys: Fundamentals and Applications. Switzerland: Springer, 2016

19 Miracle DB, Senkov ON. A critical review of high entropy alloys and related concepts. Acta Mater, 2017, 122: 448-511

20 George EP, Raabe D, Ritchie RO. High-entropy alloys. Nat Rev Mater, 2019, 4: 515-534

21 Huang S, Huang $\mathrm{H}, \mathrm{Li} \mathrm{W}$, et al. Twinning in metastable highentropy alloys. Nat Commun, 2018, 9: 2381

22 Gludovatz B, Hohenwarter A, Catoor D, et al. A fracture-resistant high-entropy alloy for cryogenic applications. Science, 2014, 345: $1153-1158$

$23 \mathrm{Wu}$ Z, Bei H, Pharr GM, et al. Temperature dependence of the mechanical properties of equiatomic solid solution alloys with face-centered cubic crystal structures. Acta Mater, 2014, 81: 428441

24 Bracq G, Laurent-Brocq M, Perrière L, et al. The fcc solid solution stability in the $\mathrm{Co}-\mathrm{Cr}-\mathrm{Fe}-\mathrm{Mn}-\mathrm{Ni}$ multi-component system. Acta Mater, 2017, 128: 327-336

25 Niu C, LaRosa CR, Miao J, et al. Magnetically-driven phase transformation strengthening in high entropy alloys. Nat Commun, 2018, 9: 1363

26 Senkov ON, Woodward CF. Microstructure and properties of a refractory $\mathrm{NbCrMo}_{0.5} \mathrm{Ta}_{0.5} \mathrm{TiZr}$ alloy. Mater Sci Eng-A, 2011, 529: 311-320

27 Senkov ON, Scott JM, Senkova SV, et al. Microstructure and elevated temperature properties of a refractory TaNbHfZrTi alloy. J Mater Sci, 2012, 47: 4062-4074

28 Zou Y, Ma H, Spolenak R. Ultrastrong ductile and stable highentropy alloys at small scales. Nat Commun, 2015, 6: 7748

$29 \mathrm{Ma} \mathrm{E}, \mathrm{Wu}$ X. Tailoring heterogeneities in high-entropy alloys to promote strength-ductility synergy. Nat Commun, 2019, 10: 5623

30 Takeuchi A, Wada T, Kato H. High-entropy alloys with hexagonal close-packed structure in $\operatorname{Ir}_{26} \mathrm{Mo}_{20} \mathrm{Rh}_{22.5} \mathrm{Ru}_{20} \mathrm{~W}_{11.5}$ and $\mathrm{Ir}_{25.5} \mathrm{Mo}_{20}$ $\mathrm{Rh}_{20} \mathrm{Ru}_{25} \mathrm{~W}_{9.5}$ alloys designed by sandwich strategy for the valence electron concentration of constituent elements in the periodic chart. Mater Trans, 2019, 60: 1666-1673

31 Zhang $\mathrm{F}, \mathrm{Wu} \mathrm{Y}$, Lou $\mathrm{H}$, et al. Polymorphism in a high-entropy alloy. Nat Commun, 2017, 8: 15687

32 Yusenko KV, Riva S, Carvalho PA, et al. First hexagonal close packed high-entropy alloy with outstanding stability under extreme conditions and electrocatalytic activity for methanol oxidation. Scripta Mater, 2017, 138: 22-27

33 Tracy CL, Park S, Rittman DR, et al. High pressure synthesis of a hexagonal close-packed phase of the high-entropy alloy CrMnFeCoNi. Nat Commun, 2016, 8: 15634

34 Li RX, Qiao JW, Liaw PK, et al. Preternatural hexagonal highentropy alloys: A review. Acta Metall Sin (Engl Lett), 2020, 33: 1033-1045

35 Youssef KM, Zaddach AJ, Niu C, et al. A novel low-density, high- hardness, high-entropy alloy with close-packed single-phase nanocrystalline structures. Mater Res Lett, 2014, 3: 95-99

36 Singh S, Wanderka N, Murty BS, et al. Decomposition in multicomponent AlCoCrCuFeNi high-entropy alloy. Acta Mater, 2011, 59: $182-190$

37 Shun TT, Chang LY, Shiu MH. Microstructures and mechanical properties of multiprincipal component $\mathrm{CoCrFeNiTi} i_{x}$ alloys. Mater Sci Eng-A, 2012, 556: 170-174

38 Ding HY, Yao KF. High entropy $\mathrm{Ti}_{20} \mathrm{Zr}_{20} \mathrm{Cu}_{20} \mathrm{Ni}_{20} \mathrm{Be}_{20}$ bulk metallic glass. J Non-Crystal Solids, 2013, 364: 9-12

39 Takeuchi A, Amiya K, Yubuta K. Partially-devitrified icosahedral quasicrystalline phase in $\mathrm{Ti}_{33.33} \mathrm{Zr}_{33.33} \mathrm{Hf}_{13.33} \mathrm{Ni}_{20}$ and $\mathrm{Zr}_{30} \mathrm{Hf}_{30} \mathrm{Ni}_{15}$ $\mathrm{Cu}_{10} \mathrm{Ti}_{15}$ amorphous alloys with near equi-atomic compositions. Mater Chem Phys, 2018, 210: 245-250

40 Li C, Li JC, Zhao M, et al. Effect of alloying elements on microstructure and properties of multiprincipal elements high-entropy alloys. J Alloys Compd, 2009, 475: 752-757

41 Wu JS, Kuo KH. A structural model of the orthorhombic $\mathrm{Ga}_{7} \mathrm{Mn}_{5}$ derived from its HREM image. Micron, 2000, 31: 459-467

$42 \mathrm{He} \mathrm{Z}, \mathrm{Ma} \mathrm{H}, \mathrm{Li} \mathrm{H}$, et al. New type of Al-based decagonal quasicrystal in $\mathrm{Al}_{60} \mathrm{Cr}_{20} \mathrm{Fe}_{10} \mathrm{Si}_{10}$ alloy. Sci Rep, 2016, 6: 22337

43 Tsai AP, Inoue A, Masumoto T. New decagonal Al-Ni-Fe and AlNi-Co alloys prepared by liquid quenching. Mater Trans JIM, 1989, 30: $150-154$

44 Tsai AP, Inoue A, Masumoto T. Stable decagonal Al-Co-Ni and Al-Co-Cu quasicrystals. Mater Trans JIM, 1989, 30: 463-473

45 Bendersky L. Quasicrystal with one-dimensional translational symmetry and a tenfold rotation axis. Phys Rev Lett, 1985, 55: 1461-1463

46 Steurer W. Twenty years of structure research on quasicrystals. Part I. Pentagonal, octagonal, decagonal and dodecagonal quasicrystals. Z für Kristallogr, 2004, 219: 391-446

47 Li XZ, Kuo KH. Orthorhombic crystalline approximants of the Al-Mn-Cu decagonal quasicrystal. Philos Mag B, 1992, 66: 117-124

$48 \mathrm{Li} \mathrm{H}, \mathrm{Ma} \mathrm{H}, \mathrm{Hou} \mathrm{L}$, et al. Shield-like tile and its application to the decagonal quasicrystal-related structures in Al-Cr-Fe-Si alloys. J Alloys Compd, 2017, 701: 494-498

49 Hiraga K, Yasuhara A. Arrangements of transition-metal atoms in three types of Al-Co-Ni decagonal quasicrystals Studied by Cscorrected HAADF-STEM. Mater Trans, 2013, 54: 493-497

50 Mizutani U. The Hume-Rothery rules for structurally complex alloy phases. In: Belinferre E, Ed. Surface Properties and Engineering of Complex Intermetallics. Singapore: World Scientific, 2010, 323-399

51 Yang X, Zhang Y. Prediction of high-entropy stabilized solidsolution in multi-component alloys. Mater Chem Phys, 2012, 132: 233-238

52 Zhang Y, Zhou Y, Lin J, et al. Solid-solution phase formation rules for multi-component alloys. Adv Eng Mater, 2008, 10: 534-538

53 Ye YF, Wang Q, Lu J, et al. High-entropy alloy: Challenges and prospects. Mater Today, 2016, 19: 349-362

Acknowledgements This work was supported by the National Natural Science Foundation of China (51871015 and 51471024), and the Selfdetermined Project of the State Key Laboratory for Advanced Metals and Materials (2016Z-13). We thank Liwen Bianji, Edanz Group China for editing the English text of a draft of this manuscript.

Author contributions $\mathrm{He} \mathrm{Z}$ conceived the research; Ma $\mathrm{H}$ and Zhao L performed the main experiments; He Z, Ma H, Zhao L and Li R wrote 
the manuscript. All authors analyzed the data, discussed the results, and drew the conclusions.

Conflict of interest The authors declare that they have no conflict of interest.

Supplementary information Supporting data are available in the online version of the paper.

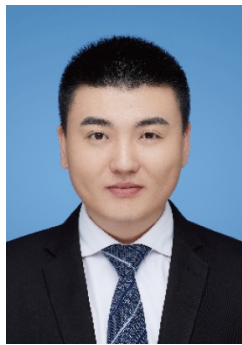

Haikun Ma is a $\mathrm{PhD}$ student at the State Key Laboratory for Advanced Metals and Materials, University of Science \& Technology Beijing (USTB), under Prof. He's supervision. His research interest focuses on TEM and quasicrystals.

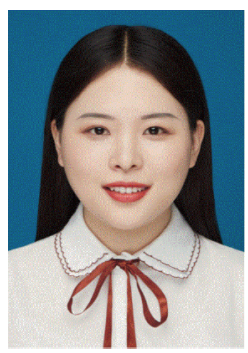

Liangqun Zhao received her Bachelor degree (2017) from Anhui University of Technology and Master degree (2020) from USTB. Her current research interest focuses on quasicrystals and high-entropy alloys.

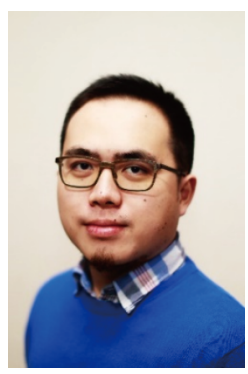

Zhi-Yi Hu is an associate professor in the $\mathrm{Na}$ nostructure Research Centre (NRC) and the State Key Laboratory of Advanced Technology for Materials Synthesis and Processing at Wuhan University of Technology. He received his PhD degree in physics from the Electron Microscopy for Materials (EMAT) research group at the University of Antwerp in 2016. His research focuses on the application of advanced electron microscopy to materials, including nanostructured materials, porous materials and catalyst materials particularly.

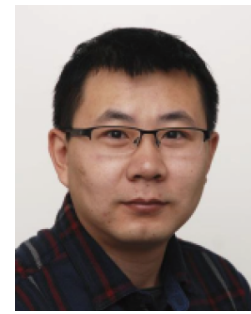

He Tian received his $\mathrm{PhD}$ degree from the Institute of Physics and Center for Condensed Matter Physics (CAS), China, in 2006. Then he joined the EMAT research group at the University of Antwerp, Belgium, as a Postdoctoral Researcher. Afterwards, he joined the Center of Electron Microscope at Zhejiang University (China) in 2014 as a professor. His main research focuses on the application and development of advanced electron microscopy. His current research interests include application of electron energy loss spectra, transition metal oxides, multiferroic and ferroelectric materials and devices.

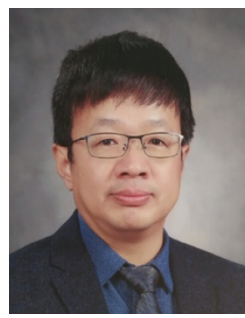

Yong Zhang has been a professor of materials science at the USTB since 2004. He has published over 200 papers, including two review papers, each of which is about 100 pages, in the journal of Progress in Materials Science (PMS). He authored a book entitled "High-entropy materials, a brief introduction" by Springer-Nature publisher. He proposed a parameter to evaluate the configurational entropy effect over the enthalpy effect at the liquid state, which has been verified multicomponent materials effective to predict the phase formation for the

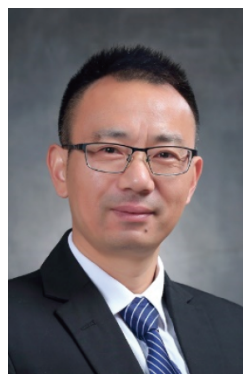

Zhanbing He received his $\mathrm{PhD}$ degree in materials science from Dalian University of Technology in 2005 under the supervision of Prof. Kehsin Kuo. He did scientific research at Stockholm University, Swiss Federal Institute of Technology in Lausanne (EPFL), and Ecole Polytechnique from 2005 to 2013 . He joined the State Key Laboratory for Advanced Metals and Materials at USTB in 2013 as a full professor. His research interest is in TEM, quasicrystals, and high-entropy alloys.

\section{$\mathrm{Al}_{20} \mathrm{Si}_{20} \mathrm{Mn}_{20} \mathrm{Fe}_{20} \mathrm{Ga}_{20}$ 中近等原子比高熵十次准晶}

马海坤 ${ }^{1 \dagger}$, 赵良群 ${ }^{1 \dagger}$, 胡执一 ${ }^{2}$, 苗定豪 ${ }^{1}$, 李荵轩 ${ }^{1}$, 孙土来 $^{3}$, 田鹤 ${ }^{3}$, 张甜甜 ${ }^{1}$, 李花 ${ }^{1}$, 张勇 ${ }^{1}$, 何战兵 ${ }^{1 *}$

摘要 准晶是结构复杂相, 通常以一种合金元素为主要成分. 高熵 合金含有多种主要合金元素，其晶体结构却往往是比较简单的立 方相. 作为结构和成分均复杂的高熵准晶却难以在实验上制备和 理论上预测, 研究人员对其结构特点也知之甚少. 因而高熵准晶的 制备和结构特性引起了人们的广泛关注. 我们报道了一种在 $\mathrm{Al}_{20} \mathrm{Si}_{20} \mathrm{Mn}_{20} \mathrm{Fe}_{20} \mathrm{Ga}_{20}$ 甩带样品中发现的含有五个主要合金元素的 近等原子比高熵十次准晶, 并对其晶体结构进行了详细表征. 该合 金和十次准晶的构型熵均满足高熵合金基于熵的判据，表明该十 次准晶是高熵准晶. 该高熵十次准晶的设计策略为高熵准晶的制 备提供了新的思路. 